\title{
Cocrystallization and Copolymerization of Diacetylenes: Some Novel Observations
}

\author{
G. G. Miller and G. N. PAtel* \\ Allied Corporation, Corporate Research Center, \\ Morristown, NJ 07960, U.S.A.
}

(Received October 7, 1980)

\begin{abstract}
The cocrystallization and copolymerization of two pairs of diacetylenes $\mathrm{R}-\mathrm{C} \equiv \mathrm{C}-\mathrm{C} \equiv \mathrm{C}-\mathrm{R}$, (1) $1 \mathrm{BU}\left[\mathrm{R}=-\mathrm{CH}_{2} \mathrm{OCONHC}_{4} \mathrm{H}_{9}\right]$ and $1 \mathrm{EU}\left[\mathrm{R}=-\mathrm{CH}_{2} \mathrm{OCONHC}_{2} \mathrm{H}_{5}\right]$, and (2) $2 \mathrm{~A}\left[\mathrm{R}=-\left(\mathrm{CH}_{2}\right)_{2} \mathrm{OH}\right]$ and $3 \mathrm{~A}\left[\mathrm{R}=\left(\mathrm{CH}_{2}\right)_{3} \mathrm{OH}\right]$ was studied by differential scanning calorimetry and reflectance spectroscopy. Several novel features were observed. $1 \mathrm{BU}$ always crystallizes into a mixture of two phases, blue $\left(\lambda_{\max }=585 \mathrm{~nm}\right)$ and red $\left(\lambda_{\max }=515 \mathrm{~nm}\right)$. 1EU and 1BU cocrystallize to form solid solutions as evidenced by singlet endotherms or by different reflectance spectra. $\lambda_{\max }$, the lowest energy optical transitions of partially polymerized cocrystallized mixtures, increases as the concentration of $1 \mathrm{EU}$ increases to about $90 \%$. Mixtures of $2 \mathrm{~A}$ and $3 \mathrm{~A}$ form amorphous solid solutions. The amorphous solid solutions crystallize in the solid state before melting. DSC shows an exotherm followed by an endotherm during heating. Partially polymerized $3 \mathrm{~A}$ changes from blue $\rightarrow$ red when touched by human hands. The color change is due to melting of unreacted monomer.
\end{abstract}

KEY WORDS Diacetylenes / Cocrystallization / Solid-State Copolymerization / Solid Solutions /

Monomers are typically gases or liquids. When monomers are solid, they are dissolved in suitable solvents for polymerization. Copolymerization of two or more monomers is usually carried out in a liquid medium containing the monomer mixture and a suitable catalyst system. The polymerization of monomers in the solid state requires that the reactive sites become adjacent to one another and that the bonding orbitals of the reacting atoms overlap. Copolymerization in the solid state is restricted to solid solutions only. In the absence of a solid solution, only homopolymers or block copolymers will result. The solid state copolymerization of both vinyl and heterocyclic monomers has been reported. ${ }^{1}$ There are few reports of solid state copolymerization of diacetylenes. ${ }^{2-4}$

Diacetylenes, $\mathrm{R}-\mathrm{C} \equiv \mathrm{C}-\mathrm{C} \equiv \mathrm{C}-\mathrm{R}$, polymerize in the solid state upon thermal annealing or through exposure to high energy radiation, ${ }^{5,6}$

* Present Address: Allied Corporation, Allied Chemical Company, Syracuse Research Laboratory, P.O. Box 6, Solvay, N.Y. 13209, U.S.A.

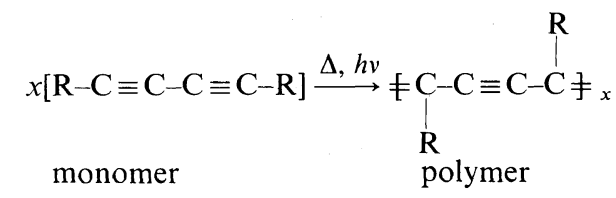

Typically, the monomers are colorless. Partially polymerized diacetylenes are either blue, purple, or red; polydiacetylenes are metallic. Polydiacetylenes are highly colored because the $\pi$ electron density is highly delocalized over the conjugated backbone. Since diacetylenes polymerize in the solid state one cannot use conventional polymerization catalysts. Polymerization of diacetylenes is initiated by radi-

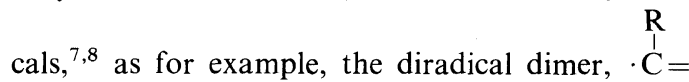
$\mathrm{R}$

$\mathrm{C}=\mathrm{C}=\underset{\mathrm{R}}{\mathrm{C}} \mathrm{C}-\mathrm{C}=\mathrm{C}=\mathrm{C}=\underset{\mathrm{R}}{\mathrm{C}} \cdot \mathrm{C} \cdot$ Radical initiators such as dicumylperoxide inhibit rather than initiate polymerization ${ }^{9}$ because first, they do not form a solid solution and second, the radicals do not become adjacent to the triple bonds. However, two isomorphous or chemically similar diacetylenes can 
cocrystallize to form a solid solution and the reactive sites can become adjacent. ${ }^{10}$ A solid solution can have a different melting point, reactivity, and color upon partial polymerization.

The polymerization of $1 \mathrm{PU}\left(\mathrm{R}=-\mathrm{CH}_{2} \mathrm{OCONH}-\right.$ (0)) by $1 p \mathrm{CPU}\left(\mathrm{R}=-\mathrm{CH}_{2} \mathrm{OCONH}-(\mathrm{O}-\mathrm{Cl})\right.$ is an excellent example of a diacetylene initiating polymerization of another. ${ }^{2}$ If crystallized from acetone or tetrahydrofuran, 1PU forms an inactive phase. This inactive phase does not polymerize upon thermal annealing or exposure to radiation. Thermal and radiation induced polymerization of $1 \mathrm{PU}$ can be increased by several orders of magnitude ${ }^{2}$ if it is cocrystallized with a few percent of $1 p \mathrm{CPU}$.

If diacetylenes are truly cocrystallized, the mixture should have a single melting point. As $1 \mathrm{PU}$ and $1 p$ CPU decompose upon melting, it was not possible to determine the melting points of these cocrystallized diacetylenes. In this paper, we report the cocrystallization and copolymerization of two pairs of diacetylenes which do not decompose upon melting.

The two pairs are (1) 3,5-octadiyn-1,8-diol $[\mathrm{R}=$ $\left.-\left(\mathrm{CH}_{2}\right)_{2} \mathrm{OH}\right]$ and 4,6-decadiyl-1,10-diol $[\mathrm{R}=$ $\left.-\left(\mathrm{CH}_{2}\right)_{3} \mathrm{OH}\right]$, referred to hereafter as $2 \mathrm{~A}$ and $3 \mathrm{~A}$ respectively and (2) 2,4-hexadiyn-1,6-bis( $n$-butyl urethane), $\left[\mathrm{R}=-\mathrm{CH}_{2} \mathrm{OCONH}\left(\mathrm{CH}_{2}\right)_{3} \mathrm{CH}_{3}\right]$ and 2,4-hexadyn-1,6-bis (ethyl urethane), $[\mathrm{R}=$ $-\mathrm{CH}_{2} \mathrm{OCONHC} \mathrm{H}_{5}$ ], referred to hereafter as $1 \mathrm{BU}$ and $1 \mathrm{EU}$ respectively. Another reason for selecting the above pairs for the present study was that $2 \mathrm{~A}$ and $3 \mathrm{~A}$ are the precursors for urethane, carboxylate, sulfonate, carboxylic, and ether derivatives; and $1 \mathrm{BU}$ and $1 \mathrm{EU}$ are excellent sensitizers for acceleration of radiation induced crosslinking of polymers. ${ }^{11}$ As diacetylenes often crystallize in more than one phase having different melting points, differential scanning calorimeter (DSC) data and visible spectra can be quite complicated.

\section{EXPERIMENTAL}

\section{Synthesis}

The Hays ${ }^{12}$ and Glaser $^{13}$ methods of oxidative coupling were used to synthesize 3,5-octadiyn-1,8diol (2A) and 4,6-decadiyn-1,10-diol (3A). Both 2A and $3 \mathrm{~A}$ were recrystallized from diethyl ether at $-20^{\circ} \mathrm{C}$ and their structures were confirmed by IR and elemental analysis. $1 \mathrm{BU}$ and $1 \mathrm{EU}$ were prepared by reacting 2,4-hexadiyn-1,6-diol with $n$-butyl isocyanate and ethyl isocyanate respectively, according to a procedure described elsewhere. ${ }^{11}$

\section{Cocrystallization}

Fifty $\mathrm{ml} \mathrm{of} 2 \%$ solutions containing different weight ratios of $2 \mathrm{~A}$ and $3 \mathrm{~A}$ were prepared in diethyl ether. Similarly, fifty $\mathrm{ml}$ of $2 \%$ solutions containing different weight ratios of $1 \mathrm{BU}$ and $1 \mathrm{EU}$ were prepared in acetone for reflectance spectroscopic studies; pieces of filter paper $\left(5 \times 7 \mathrm{~cm}^{2}\right)$ were dipped in each solution and these papers allowed to dry in air at room temperature (RT). For differential scanning calorimetry and for bulk polymerization the remainder of each solution was dried by rotary evaporator followed by vacuum drying. The four diacetylenes were polymerized by ${ }^{60} \mathrm{Co}$ $\gamma$-rays at RT. The diacetylenes coated on filter papers were polymerized thermally at RT.

\section{Instrumental}

Reflectance spectra of the thermally polymerized diacetylenes were recorded on a Perkin-Elmer UVVisible Spectrophotometer Model 200 with a reflectance sphere described elsewhere. ${ }^{14}$ A DuPont 990 Differential Scanning Colorimeter (DSC) was used to determine melting points. About $5 \mathrm{mg}$ of each sample crimped in an aluminum holder was heated at $10^{\circ} \mathrm{C} \mathrm{min}^{-1}$ under an argon atmosphere.

\section{RESULTS AND DISCUSSION}

\section{Differential Scanning Calorimetry}

Figure 1 shows DSC scans for 1EU, 1BU, and their cocrystallized mixtures during initial heating, cooling, and reheating. A small endotherm for $1 \mathrm{BU}$ at $70^{\circ} \mathrm{C}$ does not reappear upon reheating. This small endotherm is most probably due to the melting of a small fraction of an inactive phase. Except for this small endotherm, all the endotherms of $1 \mathrm{BU}, 1 \mathrm{EU}$, and their cocrystallized mixtures obtained during initial heating and reheating were almost identical. The results indicate that, whether crystallized from acetone or from melt, both the diacetylenes and their mixtures crystallize into the same phases. Cocrystallized mixtures containing 20 and $80 \% 1 \mathrm{EU}$ have doublet endotherms. It can be assumed that $1 \mathrm{EU}$ and $1 \mathrm{BU}$ have homocrystallized, a phase separation. If the diacetylenes are indeed homocrystallized, there should be corresponding exotherms during crystallization. The crystalli- 


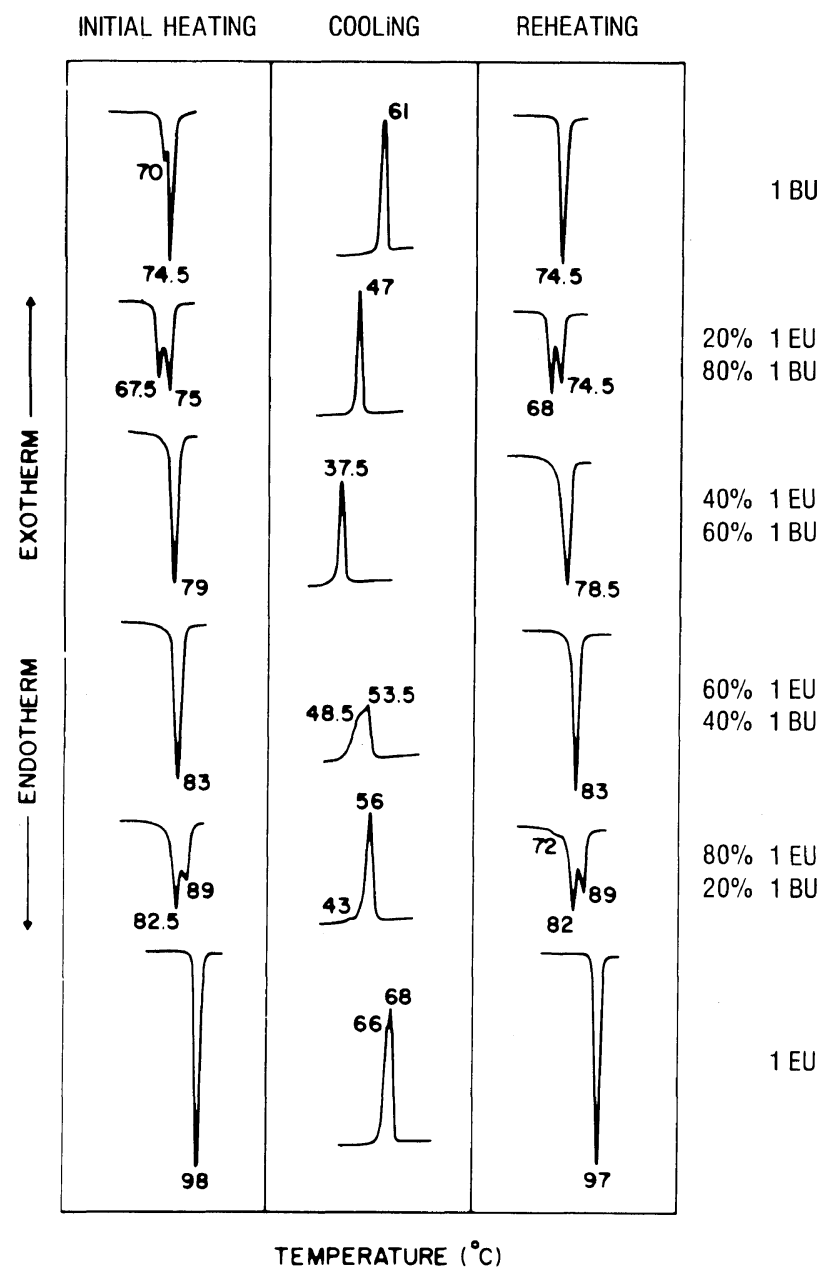

Figure 1. DSC thermograms of $1 \mathrm{EU}, 1 \mathrm{BU}$, and their cocrystallized mixtures during initial heating, cooling, and reheating.

zation temperatures of $1 \mathrm{BU}$ and $1 \mathrm{EU}$ were 61 and $67^{\circ} \mathrm{C}$ respectively. The crystallization exotherms for the mixtures are singlets at lower temperatures, $c a$. $47^{\circ}$ and $56^{\circ} \mathrm{C}$. The melting doublet endotherms of the cocrystallized mixtures do not correspond to the melting points of the pure diacetylenes. Since we found no evidence for phase separation, it is likely that both diacetylenes cocrystallized into two different solid solutions. Spectroscopic evidence supporting this conclusion is presented in Spectroscopy section.

Melting and crystallization temperatures for both the diacetylenes and their mixtures are plotted in Figure 2. The melting points of all the mixtures were intermediate between those of the pure components while the crystallization temperatures showed a minimum at about $40 \%$ of $1 \mathrm{EU}$.

DSC thermograms for $2 \mathrm{~A}, 3 \mathrm{~A}$, and their cocrystallized mixtures during initial heating, cooling, and reheating are shown in Figure 3. The melting points of these diols are close. During crystallization, they display more than one exotherm, but upon reheating, they display one endotherm.

The cocrystallized mixtures exhibited novel behavior during heating and cooling. Though we made no quantitative measurements, the DSC thermograms of the mixtures showed that the heat of fusion and the heat of crystallization decreased as 


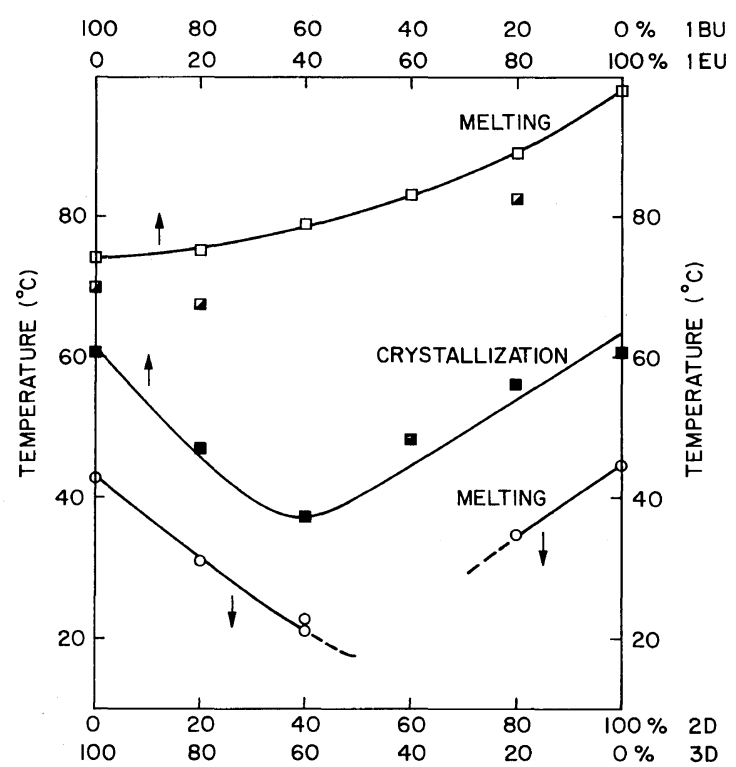

Figure 2. Plots of melting and crystallization temperatures of $1 \mathrm{EU}, 1 \mathrm{BU}$ and their cocrystallized mixtures $(\square, \boldsymbol{Z}$, and $\boldsymbol{\square})$, and melting points of $2 \mathrm{~A}$ and $3 \mathrm{~A}$ and their cocrystallized mixtures $(O)$, versus their concentration $(w / w)$. A line is not drawn for the low temperature endotherms of $1 \mathrm{EU}, 1 \mathrm{BU}$ and their mixtures ( $\mathbf{Z})$.

the concentration of $2 \mathrm{~A}$ increased up to $60 \%$. At that concentration the enthalpy of the solid liquid state transition is almost zero. The mixture solidifies and liquefies at about $-40^{\circ} \mathrm{C}$. During heating from a low temperature, about $-100^{\circ} \mathrm{C}$, the mixtures containing 40 and $80 \%$ of $2 \mathrm{~A}$ first displayed an exotherm followed by an endotherm. The mixtures are liquid at room temperature. Both the mixtures showed no exotherm during cooling. That is, they solidified into completely amorphous, solid solutions. During reheating, the mixtures first crystallized as evidenced by the exotherm and then the crystallized material melted, showing an endotherm at a higher temperature.

The size of the exotherm and the corresponding endotherm of the mixtures depends upon the heating rate. A slower heating rate $\left(c a .2 .5^{\circ} \mathrm{C} \mathrm{min}^{-1}\right)$ shows exotherms and endotherms larger than those obtained by a faster $\left(\mathrm{ca} .20^{\circ} \mathrm{Cmin}^{-1}\right)$ heating rate. The absence of exotherms and endotherms during heating and cooling the $60 \%$ mixture of $2 \mathrm{~A}$ suggests that the mixture solidified without crystallization. We believe that the formation of strong hydrogen bonds between the $-\mathrm{OH}$ groups of $2 \mathrm{~A}$ and $3 \mathrm{~A}$ in the liquid state prevents crystallization of the mixtures.

\section{Spectroscopy}

$1 \mathrm{BU}, 1 \mathrm{EU}$, and their cocrystallized mixtures polymerized to give colored polymers, either upon thermal annealing or exposure to high energy radiation. The partially polymerized diacetylenes were either blue, purple, or red while the polydiacetylenes and the copolydiacetylenes obtained by 50 Mrads of ${ }^{60} \mathrm{Co} \gamma$-rays were metallic green or copper colored. Figure 4 shows the reflectance spectra of partially polymerized $1 \mathrm{BU}, 1 \mathrm{EU}$, and their cocrystallized mixtures. 1EU partially polymerized to a pink color while $1 \mathrm{BU}$ partially polymerized to a purple color. The reflectance spectra of partially polymerized $1 \mathrm{BU}$ suggest that it crystallized into two moderately active phases. One phase partially polymerized to a red color while the other to a blue color. The spectrum of purple colored partially polymerized $1 \mathrm{BU}$ in Figure 4 is crudely resolved into its two components, red $\left(\lambda_{\max }=515 \mathrm{~nm}\right)$ and blue $\left(\lambda_{\max }=\right.$ $585 \mathrm{~nm})$.

An examination of the crystals under an optical microscope showed blue and red colored microcrystals and a small fraction of colorless crystals (the inactive phase). The colorless crystals melted just 


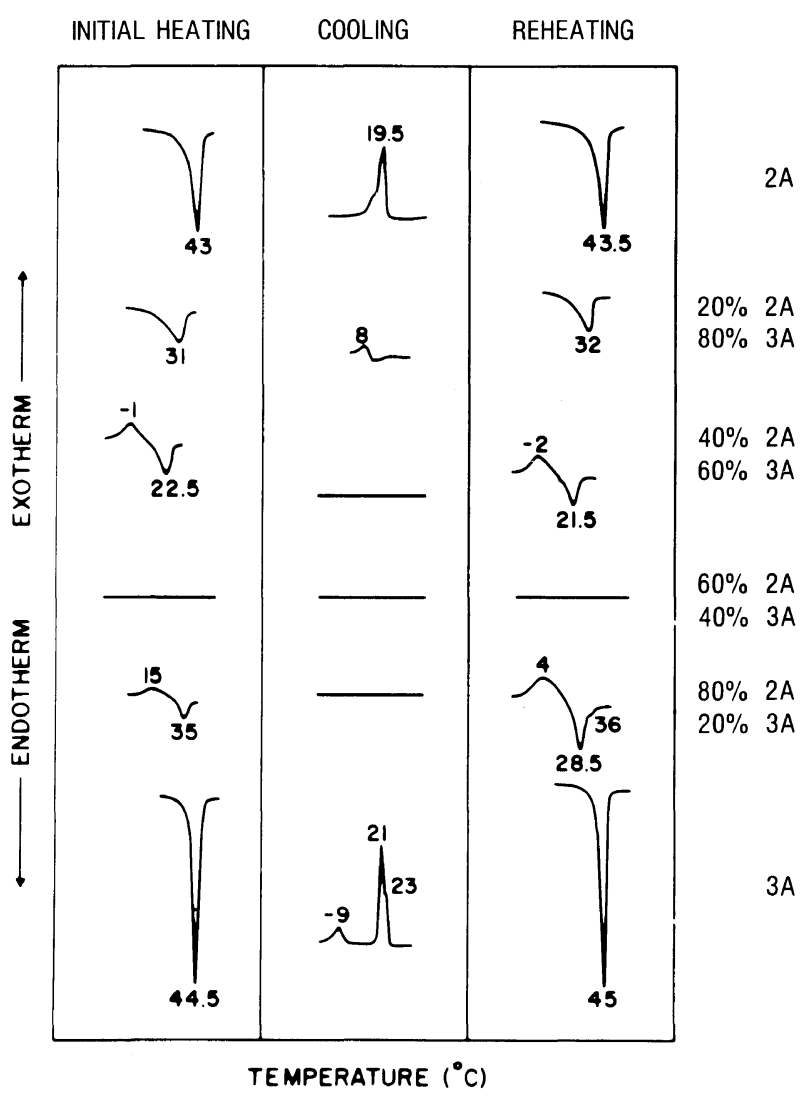

Figure 3. DSC scans of $2 \mathrm{~A}, 3 \mathrm{~A}$ and their mixtures during initial heating, cooling, and reheating.

before the blue and the red crystals. The blue and red crystals melted at the same temperature, $c a$. $75^{\circ} \mathrm{C}$. Attempts were made to grow large, isolated single crystals of the blue and the red phase from different solvents, but we always obtained mixtures of both phase.

When crystallized from melt, 1BU also crystallizes into the same two phases. However, the ratio of the blue to the red phase varies with experimental conditions. For example, predominantly red crystals are obtained from hexane or heptane, while most of the crystals are blue when crystallized from acetone, tetrahydrofuran, or from melt. Figure 5 shows the reflectance spectra of partially polymerized 1BU crystals grown from heptane and from the melt. As can be seen from Figures 4 and 5, the intensity of the peaks at 515 and $585 \mathrm{~nm}$ varies with the experimental conditions.

Both the blue and the red phases have different thermal and radiation reactivities. The red phase had a higher radiation reactivity than the blue one. The blue phase had a higher thermal reactivity than the red one. For example, when crystals grown from acetone were exposed to UV light, they appeared red because the red phase polymerized faster than the blue one. However, if the same crystals are thermally annealed, they appear blue because the blue phase polymerizes faster than the red one.

A partially polymerized diacetylene is a solid solution of unreacted monomer and polymer chains. Polymer chains in the blue colored $\left(\lambda_{\max }=\right.$ $585 \mathrm{~nm}$ ) crystals of $1 \mathrm{BU}$ are either held planar or compressed by the adjacent unreacted monomer. ${ }^{15}$ When unreacted monomer is removed by extraction with a solvent such as acetone, the strain is released and the backbone becomes either slightly nonplanar or relaxed. As a result, the residual polymer chains appear red $\left(\lambda_{\max }=540 \mathrm{~nm}\right)$, a blue shift, on the other hand, polymer chains in the red crystals $\left(\lambda_{\max }=\right.$ $515 \mathrm{~nm})$ are either relatively nonplanar or stretched 


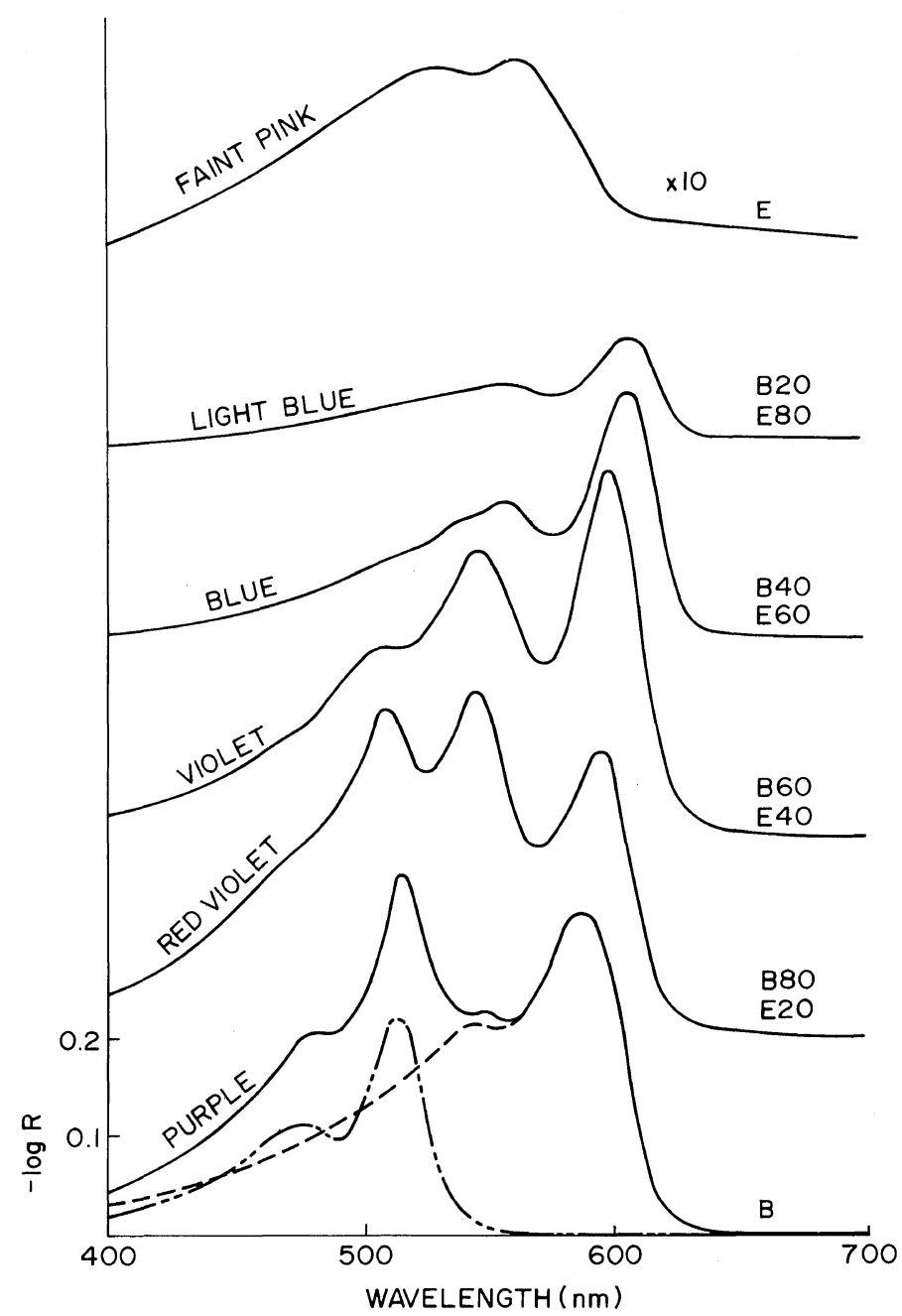

Figure 4. Reflectance Spectra of partially polymerized 1EU,1BU, and their cocrystallized mixtures. $R$ is the reflectivity and $-\log R$ is almost equivalent to the absorbance. The value of $-\log R$ at $700 \mathrm{~nm}$ was zero for all spectra. The spectrum of $1 \mathrm{BU}$ is crudely resolved into its two components, red and blue (see the text). The spectrum of $1 \mathrm{EU}$ is magnified ten times. Color and composition of diacetylenes is indicated on each spectrum. B represents $1 \mathrm{BU}$ and $\mathrm{E}$ represents $1 \mathrm{EU}$. For example, B60, E40, represents a mixture containing $60 \%$ (by weight) $1 \mathrm{BU}$ and the rest $1 \mathrm{EU}$. All compositions were polymerized at RT for two weeks before recording the spectra.

in order to maintain a solid solution. ${ }^{15}$ Upon extraction of the unreacted monomer, the backbone becomes either slightly planar or relaxes, resulting in a red shift. The residual polymer chains appear more red $\left(\lambda_{\max }=540 \mathrm{~nm}\right)$. After extraction of the untreated monomer, the conformation of the polymer chains of blue and red crystals is identical (see broken spectra in Figure 5). The blue and the red shifts of partially polymerized $1 \mathrm{BU}$ are very similar to those reported for $1 m \mathrm{TU}^{14}$ and are explained in ref 15 .

The $n$-butyl urethane of 2,4-hexadiyn-1,6-diol is a novel example of a compound which crystallizes simultaneously into two different phases each having the same melting point. Each phase polymerizes to a different color. Each phase has different ther- 


$$
\mathrm{R}=-\mathrm{CH}_{2} \mathrm{OCONH}\left(\mathrm{CH}_{2}\right)_{3} \mathrm{CH}_{3}
$$

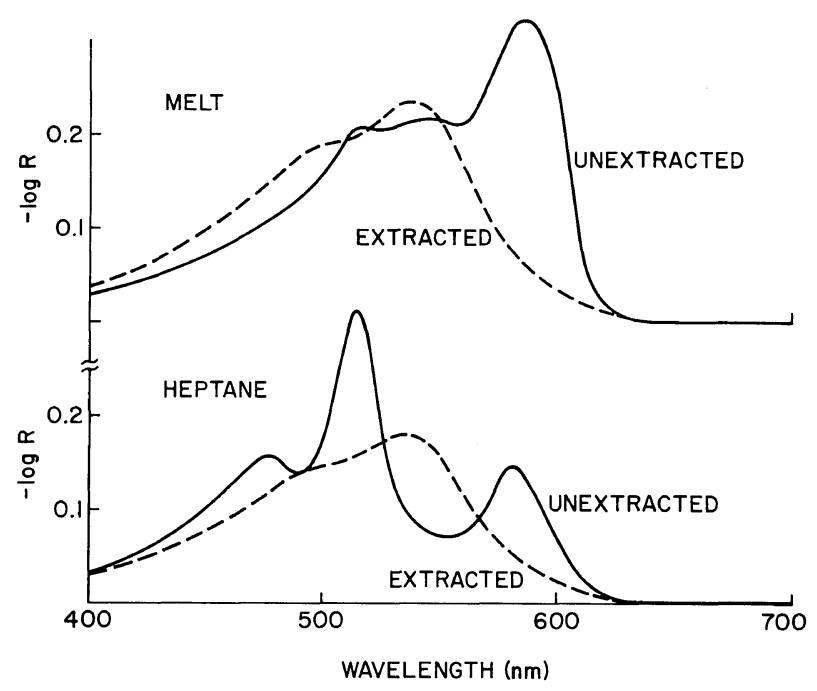

Figure 5. Reflectance spectra of partially polymerized 1BU crystallized from melt and heptane. The spectra after extraction of unreacted monomer with acetone are shown by broken lines.

mal and radiation reactivities. Diacetylenes are known to crystallize into more than one phase, and these phases are known to have different thermal and radiation reactivities. ${ }^{6}$ These different phases, however, are usually grown from different solvent systems. For example, $1 m \mathrm{TU}\left(\mathrm{R}=-\mathrm{CH}_{2} \mathrm{OCONH}-\right.$ $\left.\mathrm{CH}_{3}\right)$ to a moderately reactive orange phase from acetone/hexane and to a highly reactive blue phase from $p$-dioxane/water. In contrast, 1BU crystallizes simultaneously to moderately reactive phases having different thermal and radiation reactivities. These phases can be differentiated by spectroscopy and by optical microscopy. Previously we mistook 1BU crystallized from hexane for an isolated red phase and that crystallized from acetone for an isolated blue phase. ${ }^{11} \mathrm{X}$-ray diffraction studies are required to determine the molecular packing in the blue and the red phases of $1 \mathrm{BU}$.

Since $1 \mathrm{BU}$ crystallizes into two moderately active phases, the reflectance spectra of partially polymerized cocrystallized mixtures (Figure 4) are complicated. Cocrystallized mixtures can contain more than one solid solution or homocrystallized phases. The melting endotherm of a cocrystallized mixture containing $80 \% 1 \mathrm{BU}$ is a doublet (Figure 1) indicating at least two solid solutions. The corresponding reflectance spectrum (Figure 4) suggests that the mixture does have at least two, possibly three reactive phases. It is difficult to resolve the reflectance spectra of more than two reactive phases. The mixture containing $20 \% 1 \mathrm{BU}$ also has a doublet endotherm, but the corresponding reflectance spectrum shows that only one phase polymerizes to a blue color while the other is inactive. Another possibility, though less likely, is that both phases polymerize to the same blue color. The endotherm for the mixture containing $40 \% 1 \mathrm{BU}$ is a singlet, and the corresponding reflectance spectrum also shows a single phase. The reflectance spectrum of a mixture containing $60 \% 1 \mathrm{BU}$ indicates two reactive phases while the corresponding endotherm is a singlet.

Clearly, it is difficult to develop a relationship between the melting endotherms and the corresponding reflectance spectra of partially polymerized mixtures. However, it is interesting to note that cocrystallized diacetylenes do form solid solution. This is reflected by a continuous red shift in the reflectance spectra as the concentration of $1 \mathrm{EU}$ is increased to about $90 \%$. Figure 6 shows a plot of $\lambda_{\text {max }}$ for the lowest energy optical transition versus concentration of $1 \mathrm{EU}$. The results suggest that the backbone of the copolymer becomes more planar as 


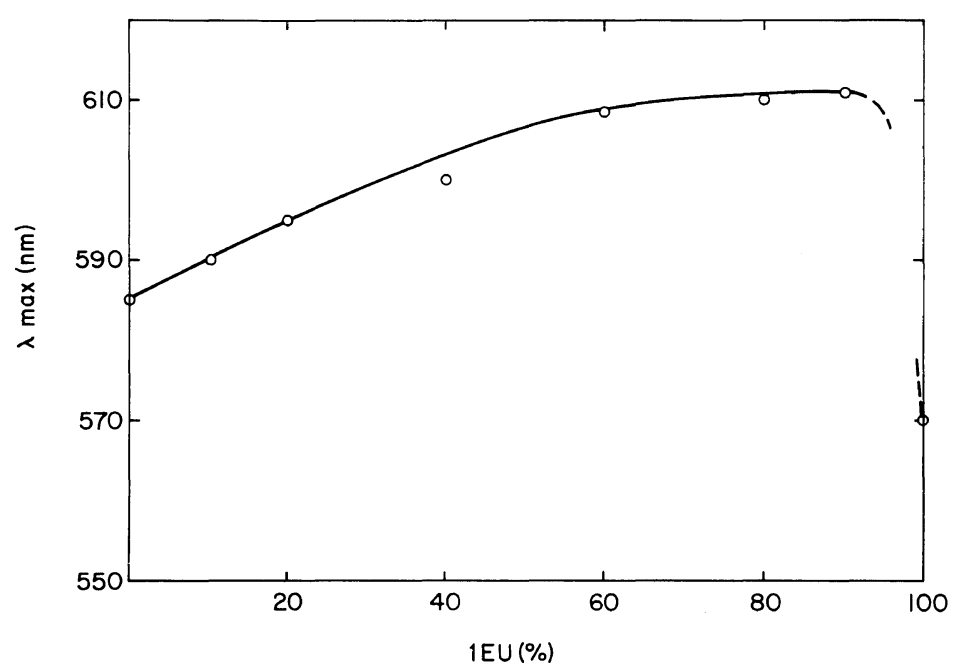

Figure 6. Plot of $\lambda_{\max }$ (lowest energy optical transition) of partially polymerized compositions versus concentration of $1 \mathrm{EU}$ (weight-percent).

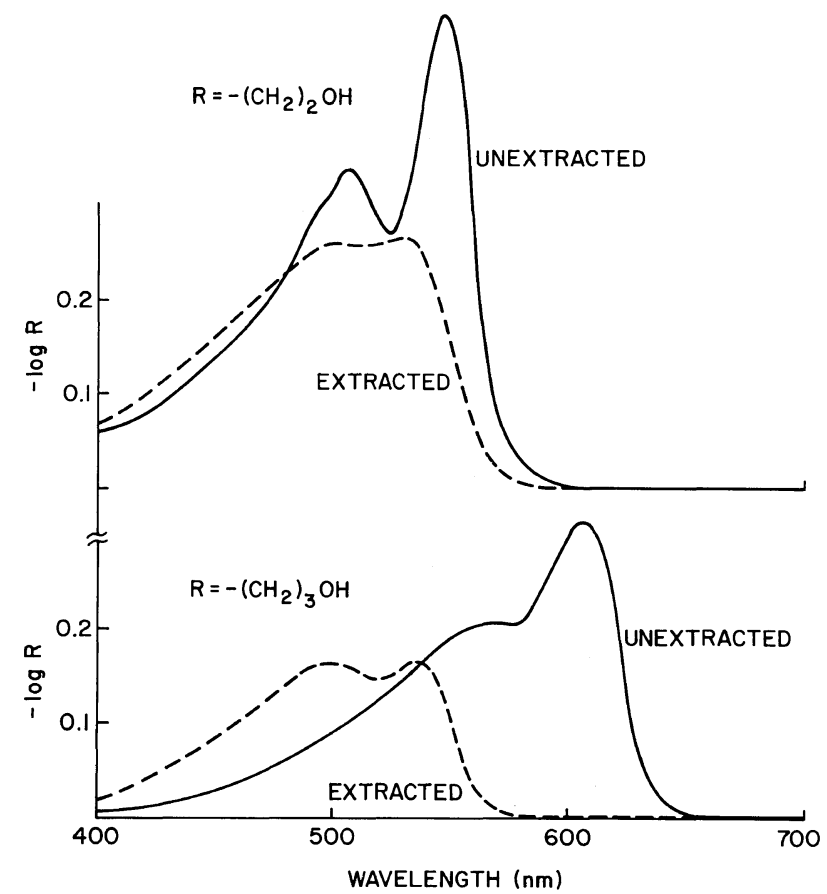

Figure 7. Reflectance spectra of partially polymerized $2 \mathrm{~A}$ and $3 \mathrm{~A}$ before (solid) and after (broken) extraction of unreacted monomer. $2 \mathrm{~A}$ is about ten times more thermally reactive than $3 \mathrm{~A}$. $2 \mathrm{~A}$ and $3 \mathrm{~A}$ were allowed to polymerize at RT for 2 and 7 days respectively before the spectra were recorded.

the concentration of $1 \mathrm{EU}$ increases. 1EU partially polymerizes to a red color $\left(\lambda_{\max }=570 \mathrm{~nm}\right)$. Cocrystallization of $1 \mathrm{EU}$ with about $10 \% 1 \mathrm{BU}$ not only increases the rate of polymerization but also increases the planarity of the resultant backbone.

Figure 7 shows the reflectance spectra of partially 
polymerized $2 \mathrm{~A}$ and $3 \mathrm{~A}$ before and after extraction of unreacted monomer. It was difficult to record the reflectance spectra of the partially polymerized cocrystallized mixtures of these diols because their melting points are below room temperature. The cocrystallized mixtures were polymerized by UV light at low temperatures. The mixture containing $80 \% 3 \mathrm{~A}$ polymerizes to a blue color if irradiated at about $-20^{\circ} \mathrm{C}$, while the other mixtures do not. These amorphous mixtures polymerize only if they are allowed to crystallize in the solid state before UV irradiation. The mixture containing $60 \% 3 \mathrm{~A}$ must be annealed at about $0^{\circ} \mathrm{C}$ for a few minutes in order to crystallize before it can be polymerized to a violet color. Likewise, the mixture containing $20 \%$ $3 \mathrm{~A}$ requires annealing at about $20^{\circ} \mathrm{C}$ before it can be polymerized by UV light to a red color. If these mixtures are irradiated above their melting points, they do not polymerize. These partially polymerized mixtures turn red upon annealing at room temperature due to the melting (extraction) of unreacted monomers.

A mixtures containing $40 \% 3 \mathrm{~A}$ does not polymerize at all even if it is annealed just below the visual melting point indicating that it remains glassy at all times.

Blue colored partially polymerized $3 \mathrm{~A}$ turns red if touched by human hands. This color change is due to the melting of unreacted monomer at about body temperature $\left(37^{\circ} \mathrm{C}\right)$; thus, partially polymerized $3 \mathrm{~A}$ makes an ideal show-and-tell item for demonstrating the color change in partially polymerized diacetylenes upon extraction of unreacted monomer.

Attempts were made to grow large crystals of the diacetylenes and their cocrystallized mixtures for X-ray diffraction study. However, we were unsuccessful in growing single crystals large enough for such a study. The active phases of diacetylenes and their cocrystallized mixtures polymerize rapid- ly upon exposure to X-rays. As a result we could not confirm the different phases of the cocrystallized mixtures.

Acknowledgement. The authors are grateful to Donald W. Richardson for the DSC experiments and Dr. E. Turi and Dr. R. H. Baughman for their helpful discussions.

\section{REFERENCES}

1. J. E. Herz and V. Stannett, J. Polym. Sci., Polym. Phys. Ed., 3, 1 (1969); Y. Tabata, "Advances in Macromolecular Chemistry," Vol. 1, W. M. Pasika, Ed., Academic Press, New York, 1968.

2. G. G. Miller and G. N. Patel, J. Appl. Polym. Sci., 24, 883 (1979).

3. V. Enkelmann, Makromol. Chem., 179, 2811 (1978).

4. V. Enkelmann, J. Mater. Sci., 15, 651 (1980).

5. G. Wegner, Z. Naturforsch, B24, 824 (1969); Makromol. Chem., 134, 219 (1970); ibid., 145, 85 (1971); ibid., 154, 35 (1979).

6. G. Wegner, "Molecular Metals," W. E. Hatfield, Ed., Plenum Press, New York, 1979, pp 209-242.

7. G. N. Patel, R. R. Chance, E. A. Turi, and Y. P. Khanna, J. Am. Chem. Soc., 100, 6644 (1978).

8. Y. Hori and L. D. Kispert, J. Am. Chem. Soc., 101, 3173 (1979).

9. G. N. Patel, unpublished paper.

10. G. N. Patel, US Patent $4,164,458$, assigned to Allied Chemical Corporation, U.S.A., February 1980.

11. G. N. Patel, Radiat. Phys. Chem., 14, 729 (1979).

12. A. S. Hay, J. Org. Chem., 27, 3320 (1962).

13. J. B. Armitage, C. L. Cook, N. Entwistle, E. R. H. Jones, and M. C. Whiting, J. Chem. Soc. (London), 1998 (1952).

14. G. N. Patel, E. N. Duesler, D. Y. Curtin, and I. C. Paul, J. Am. Chem. Soc., 102, 461 (1980).

15. G. N. Patel and G. G. Miller, J. Macromol. Sci., Phys., in press. The relationship between color and conformation of polydiacetylenes is explained in this reference. 